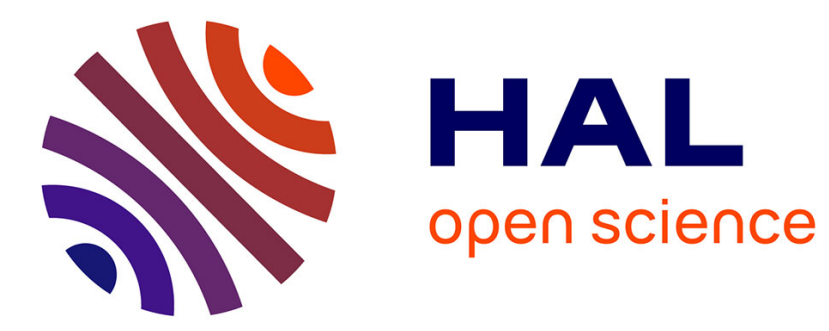

\title{
Phase Stability of Martensitic Structures
}

M. Ahlers

\section{To cite this version:}

M. Ahlers. Phase Stability of Martensitic Structures. Journal de Physique IV Proceedings, 1995, 05

(C8), pp.C8-71-C8-80. 10.1051/jp4:1995808 . jpa-00254056

\section{HAL Id: jpa-00254056 https://hal.science/jpa-00254056}

Submitted on 1 Jan 1995

HAL is a multi-disciplinary open access archive for the deposit and dissemination of scientific research documents, whether they are published or not. The documents may come from teaching and research institutions in France or abroad, or from public or private research centers.
L'archive ouverte pluridisciplinaire HAL, est destinée au dépôt et à la diffusion de documents scientifiques de niveau recherche, publiés ou non, émanant des établissements d'enseignement et de recherche français ou étrangers, des laboratoires publics ou privés. 


\title{
Phase Stability of Martensitic Structures
}

\author{
M. Ahlers \\ Centro Atómico Bariloche and Instituto Balseiro, Comisión Nacional de Energía Atómica, 8400 S.C. de \\ Bariloche, Argentina
}

\begin{abstract}
In the first part of the paper the relative stabilities of the different martensitic phases, mainly in $\mathrm{Cu}-\mathrm{Zn}-\mathrm{Al}$, are compared. It is shown that the differences in enthaipy of formation between the fcc type $3 \mathrm{R}$ or $6 \mathrm{R}$ and the $9 \mathrm{R}, 18 \mathrm{R}$ or $2 \mathrm{H}$ structures are above all due to a lattice distortion which reduces the energy per stacking fault, considering $9 \mathrm{R}, 18 \mathrm{R}$ and $2 \mathrm{H}$ as a basic face centered lattice into which faults are introduced on each third or second plane. In the second part the factors are discussed which are important in the relative stabilities not only between the matrix and martensite phases, but also for the equilibrium phases in the noble metal alloys. These are; i) the vibrational entropy difference $\Delta S$, which is a function mainly of electron concentration e/a. It depends little, if at all, on the special alloy system, on the degree of long range order, or on temperature; ii) the stability of the average periodic lattice which is a smooth function of $\mathrm{e} / \mathrm{a}$, without any indication of nesting effects at intermediate e/a; iii) the pair interchange energies which depend strongly on the alloy system. They are a function of the pair distance but otherwise are structure independent. They determine most of the enthalpy of formation and simultaneously account for the long range order contribution.
\end{abstract}

\section{INTRODUCTION}

A knowledge of the factors which control the stability of martensitic phases is not only interesting from a scientific point of view, but is essential for the prediction and evaluation of materials for technological applications. Martensite structures are the result of a martensitic transformation. The latter can be roughly subdivided into those which involve a large hysteresis between transformation and retransformation, and those for which the hysteresis is so small that equilibrium transformation temperatures and stresses can be defined with sufficient precision. To them belong the shape memory alloys (SMA), which will be exclusively considered in this paper.

Furthermore the discussion will be restricted to alloys whose high temperature equilibrium phase is bcc. Among them the alloys based on the noble metals $\mathrm{Cu}, \mathrm{Ag}$ and $\mathrm{Au}$ form a large and important group. Since for them most information is available, and since our own research has centered on the $\mathrm{Cu}-\mathrm{Zn}-\mathrm{Al}$ system, it seems appropriate to start with a discussion of the factors which determine the martensitic transformation in $\mathrm{Cu}-\mathrm{Zn}-\mathrm{Al}$ alloys, followed by a comparison with other noble metal alloys. Other SME alloys as $\mathrm{Ni}-\mathrm{Ti}$ and $\mathrm{Ni}-\mathrm{Al}$ have to remain outside this discussion for lack of space.

In the noble metal alloys the high temperature matrix phase is disordered bcc at elevated temperatures. At a critical ordering temperature $T_{c}{ }^{B} 2$, long range ordering in first neighbors to $B 2$ occurs. Depending on composition, ordering in second neighbors can also take place, leading to the $\mathrm{L} 2{ }_{1}$ structure. The degree of long range order can be manipulated to some extent by thermal treatments. Three different martensitic structures are commonly observed, depending on composition and/or applied stress. They can be considered as different stacking sequences of close packed planes. For the $3 \mathrm{R}$ martensite with inherited B2 order, the stacking sequence is $\mathrm{A} \mathrm{B} \mathrm{C}$. When $\mathrm{L} 2_{1}$ order is present the sequence is doubled and $6 \mathrm{R}$ is obtained. The 9R has A B C B C A C A B stacking which increases twofold in 18R with $\mathrm{L} 2{ }_{1}$ order. The $2 \mathrm{H}$ has the A B A B stacking for an inherited B2 and L2, order. The three types of structures can be considered as a basic fct lattice into which stacking faults are introduced on every third plane for $9 \mathrm{R}$ and 
$18 \mathrm{R}$, and on every second one for $2 \mathrm{H}$. This concept is very useful as will be shown later. Before the question of what determines the differences in phase stability between the high temperature bcc $\beta$ phase and the martensites can be tackled, the differences between martensitic phases have to be evaluated. This will be done first, starting with the observations for $\mathrm{Cu}-\mathrm{Zn}-\mathrm{Al}$.

\section{THE TRANSFORMATION BETWEEN THE MARTENSITIC PHASES}

Detailed measurements of the stresses which are necessary to transform one structure into the other are now available for a large composition range in $\mathrm{Cu}-\mathrm{Zn}-\mathrm{Al}$ alloys. From them equilibrium stresses can be deduced [1]. It has been shown that they depend little on temperature, which implies that the entropy difference, according to the Clausius Clapeyron relationship, is so small that it cannot be determined reliably from the experiments and generally is neglected [1]. It is therefore the enthalpy which mainly differs in the three structures.
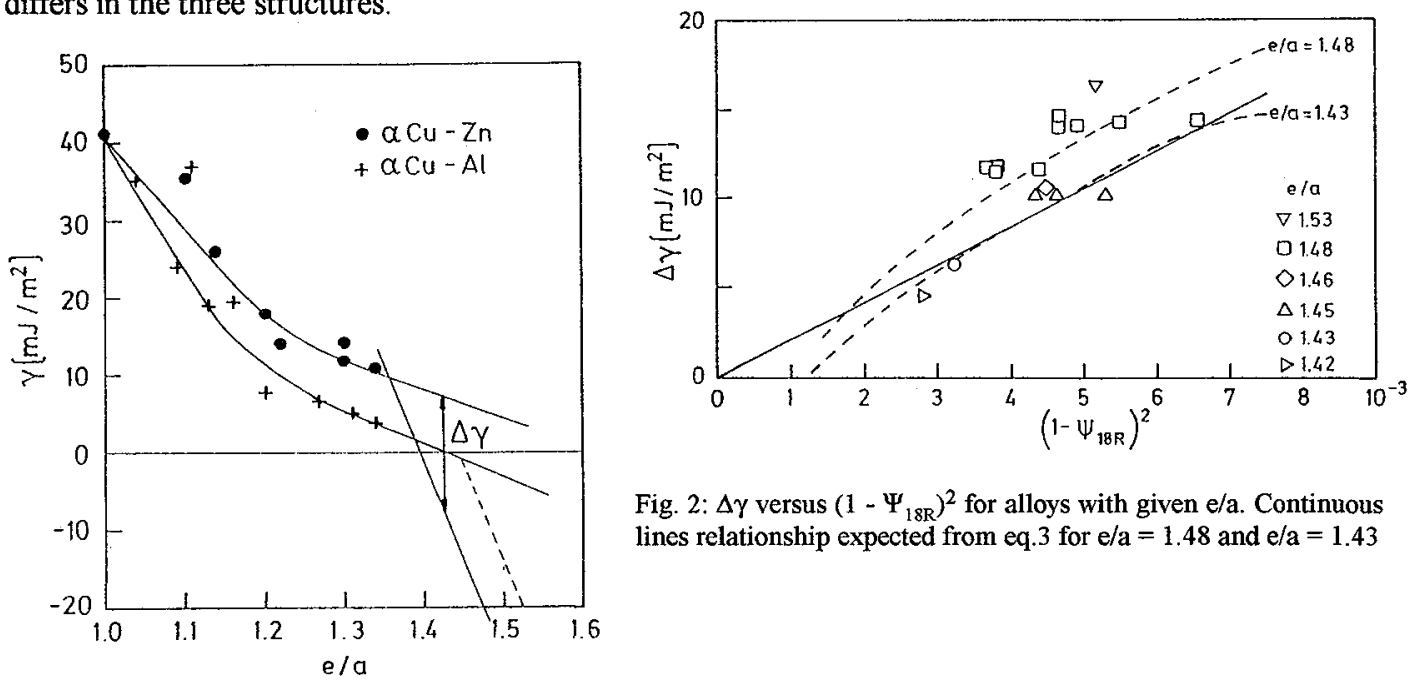

Fig. 2: $\Delta \gamma$ versus $\left(1-\Psi_{18 R}\right)^{2}$ for alloys with given e/a. Continuous lines relationship expected from eq. 3 for $e / a=1.48$ and $e / a=1.43$

Fig.1: Stacking fault energy for disordered $\alpha$ phase $\mathrm{Cu}-\mathrm{Zn}$ and $\mathrm{Cu}-\mathrm{Al}$, and energy per fault in $18 \mathrm{R}$ martensite extrapolated to binary $\mathrm{Cu}-\mathrm{Zn}$ and $\mathrm{Cu}-\mathrm{Al}$. $\Delta \gamma$ difference between both.

Measurements of the lattice parameters in single crystals $[2,3]$ have shown that the phase stabilities between the martensites cannot be understood without taking into consideration the lattice parameter changes. It is surprising that the tetragonality of the basic fct lattice, into which the faults are introduced, differ so much for the three different types of lattices. Whereas the $3 R$ and $6 R$ crystals are cubic in the absence of faults [3], the basic fet lattice for $9 \mathrm{R}, 18 \mathrm{R}$ and $2 \mathrm{H}$ is tetragonally distorted with (c/a) fet around 0.93 , which varies noticeably with composition [2]. If the transformation had proceeded from a disordered A2 bcc phase, the resulting martensite would be cubic, with or without faults. It is therefore the long range order that leads to a tetragonal distortion. However, the long range order contribution to the enthalpy of formation stems mainly from the pair interchange energies due to first and second nearest neighbor pairs, which are not affected when the stacking sequence is modified from that of an fcc lattice. The reason for the differences in the enthalpy of formation between the fcc $3 R$ or $6 R$ and the $9 R, 18 R$ or $2 \mathrm{H}$ cannot be sought in a change of order energy; because very high third neighbor pair interchange energies would be required. They must be related to long range order in a different and more subtle way, which will be dealt with below.

The concept of considering the $9 \mathrm{R}, 18 \mathrm{R}$ and $2 \mathrm{H}$ martensites as a basic fet lattice into which a regular array of stacking faults has been introduced on each third or second plane is not only a formal one, since it has been established that the composition and long range order dependence of the energy per stacking fault 
is the same for $9 \mathrm{R}$ or $18 \mathrm{R}$ and for $2 \mathrm{H}$ in $\mathrm{Cu}-\mathrm{Zn}-\mathrm{Al}$ [1], i.e. is independent of the stacking fault density. This suggests that a single stacking fault in the fct matrix also has the same composition dependence. Since, as mentioned above, the order energy does not affect, or affects only slightly, the stacking fault energy, it seems possible to compare the composition dependence of the energy per fault in ordered 9R or $18 \mathrm{R}$ with that of a single fault in disordered $\alpha$ phase fcc solid solution. This is done in figure 1 for binary $\mathrm{Cu}-\mathrm{Zn}$ and $\mathrm{Cu}-\mathrm{Al}$. The $\alpha$ phase stacking fault energy has been determined by transmission electron microscopy from extended dislocation nodes [4], and that for $9 \mathrm{R}$ or $18 \mathrm{R}$ has been extrapolated from the ternary $\mathrm{Cu}-\mathrm{Zn}-\mathrm{Al}$ alloys. It can be noted that the composition dependence is very different for both. It is tempting to associate this difference with the observed tetragonal distortion of the basic fct lattice for $9 \mathrm{R}$ and $18 \mathrm{R}$. It will be shown in the following pages that all observations can be rationalized in a consistent way if it is assumed that by the tetragonal distortion the stacking fault energy is reduced. If the distortion energy between the cubic and the fct lattice is described, in first approximation, by an elastic distortion, then it can be expected that it is proportional to $\left(1-(\mathrm{c} / \mathrm{a})_{\mathrm{ft}}\right)^{2}$, and that therefore a linear relationship between the difference in stacking fault energy $\Delta \gamma$ of figure 1 and $\left(1-(\mathrm{c} / \mathrm{a})_{\mathrm{fet}}\right)^{2}$ exists.

In figure 2 are plotted experimental data of $(\mathrm{c} / \mathrm{a})_{\mathrm{fct}} \equiv \Psi_{18 \mathrm{R}}$ for the ternary $\mathrm{Cu}-\mathrm{Zn}$-Al single crystals $[2,3]$ versus $\Delta \gamma . \Delta \gamma$ has been obtained by subtracting from the measured enthalpy per stacking fault in 18R [1] the contribution for the disordered $\alpha$ phase, which has been linearly interpolated between the binary systems [5].

$$
\gamma_{\text {dis }}=67-41.67(\mathrm{e} / \mathrm{a})-16 \mathrm{C}_{\mathrm{A} 1} /(\mathrm{e} / \mathrm{a}-1)\left[\frac{\mathrm{mJ}}{\mathrm{m}^{2}}\right]
$$

It can be noted in figure 2 that there is a large scatter in the data. A reason for this is that $\Psi_{18 R}$ depends slightly on heat treatment in the $\beta$ phase, and thus is amplified when $\left(1-\Psi_{18 R}\right)^{2}$ is required [3]. It has been argued that the highest degree of $\mathrm{B} 2$ order corresponds to the highest tetragonal distortion $\left(1-\Psi_{18 R}\right)$ of a given composition, and that this is reached only when after quenching or cooling from high temperatures the samples are moderately reheated [3]. Through these data points a linear relationship is much better defined, and from figure 2 we obtain

$$
\Delta \gamma=2140\left(1-\Psi_{18 \mathrm{R}}\right)^{2}\left[\mathrm{~mJ} / \mathrm{m}^{2}\right] \quad\left(\Psi_{18 \mathrm{R}} \equiv(\mathrm{c} / \mathrm{a})_{\mathrm{fct}}\right)
$$

In figure 2 we have also plotted as continuous lines the relationship that would be expected for $\mathrm{e} / \mathrm{a}=1.48$ and $\mathrm{e} / \mathrm{a}=1.43$, if the linear dependence between $\mathrm{M}_{\mathrm{S}}$ and $\Psi_{18 \mathrm{R}}$, reported in [6], holds:

$$
\mathrm{M}_{S}\left[{ }^{\circ} \mathrm{C}\right]=457-7320\left(1-\Psi_{18 \mathrm{R}}\right)
$$

It can be noted that these curves pass quite well through the single crystal data when no special care is taken to improve the B2 order.

To derive eq. 2 it has been assumed that $\Delta \gamma$ becomes zero when $\Psi_{18 \mathrm{R}}=1$. This may not be exactly true since in the regular array of stacking faults on each third plane some interactions may be present which are independent of the degree of order. However, this contribution is expected to be small, for the following reason: when comparing the energy per fault in $2 \mathrm{H}$ and in $9 \mathrm{R}$ or $18 \mathrm{R}$, only a small difference of $11 \mathrm{~m} \mathrm{~J} / \mathrm{m}^{2}$ is observed, independent of composition and of long range order in the alloys studied [1]. It seems reasonable to expect that this energy is due mainly to the unfavourable interaction between the faults on each second plane in $2 \mathrm{H}$, whereas the more widely spaced faults on each third plane in $9 \mathrm{R}$ and $18 \mathrm{R}$ interact much less, if at all. For this reason $\Delta \gamma$ has been assumed to be close to zero when $\Psi_{18 \mathrm{R}}=1$. From the plot of figure 2 alone it cannot be proved that $\Delta \gamma$ depends quadratically on $\left(1-\Psi_{18 \mathrm{R}}\right)$. A linear relationship could as well account for the results, as proposed in [3]. However, such a dependence would imply that $\Delta \gamma$ becomes zero at $\Psi_{18 \mathrm{R}} \neq 1$, which is less satisfactory. A second argument will be given below.

The tetragonal distortion would be absent when no long range order existed. It is clear that $\Psi_{18 \mathrm{R}}$ is somehow related to order. Without specifying the mechanism it had therefore been proposed [5] that $\Delta \gamma$ should also be a function of the B2 inherited order energy (ordering in second neighbors in the $\beta$ phase does not affect $\Delta \gamma$ ). The long range order contribution to the enthalpy of the fcc martensite with inherited $\mathrm{B} 2$ order (see [7]) is 


$$
H_{2}^{\alpha}-H_{d i s}^{\alpha}=\left(2 m_{\mathrm{CuZn}}^{(1)}-3 m_{\mathrm{CuZn}}^{(2)}\right)\left(X_{\mathrm{Cu}} X_{\mathrm{Zn}}+\frac{2 m_{\mathrm{CuAl}}^{(1)}-3 m_{\mathrm{CuAl}}^{(2)}}{2 \mathrm{~m}_{\mathrm{CuZn}}^{(1)}-3 \mathrm{~m}_{\mathrm{CuZn}}^{(2)}} X_{\mathrm{Cu}} X_{\mathrm{Al}}\right)
$$

Here, the contribution of the $\mathrm{Zn}-\mathrm{Al}$ pairs has been neglected, and $\mathrm{X}_{\mathrm{A}}$ are the relevant long range order parameters, which are related to composition for perfect order according to

In figure 3 is plotted $\Delta \gamma$ versus $\mathrm{O}_{2.25}$, with

$$
\mathrm{X}_{\mathrm{Cu}}=\mathrm{C}_{\mathrm{Zn}}+\mathrm{C}_{\mathrm{Al}}, \mathrm{X}_{\mathrm{Zn}}=-\mathrm{C}_{\mathrm{Zn}}, \mathrm{X}_{\mathrm{Al}}=-\mathrm{C}_{\mathrm{A} \downarrow}
$$

$$
-\mathrm{O}_{2.25}=\mathrm{X}_{\mathrm{Cu}} \mathrm{X}_{\mathrm{Zn}}+2.25 \mathrm{X}_{\mathrm{Cu}} \mathrm{X}_{\mathrm{Al}}
$$

The factor 2.25 gives the best fit and is further justified later on. It can be noted from figure 3 that there is an excellent correlation with a scatter of about $1 \mathrm{~mJ} / \mathrm{m}^{2}$, which is the uncertainty in the individual measurements. A relationship

$$
\Delta \gamma=400 . O_{2.25}-53.6\left[\mathrm{~mJ} / \mathrm{m}^{2}\right]
$$

is therefore proposed. This relationship is not completely satisfactory, since it implies that $\Delta \gamma$ becomes zero when long range order is still present at $\mathrm{O}_{2.25}=0.134$. 'In addition this eq. cannot account for changes in $\Psi_{18 \mathrm{R}}$ during stabilisation [3]. Therefore eq. 7 cannot be considered as the fundamental equation that controls the enthalpy differences between the different martensitic structures. This result can be taken as a further support for the assertion that the most important factor in changing the stacking fault energy is the tetragonal distortion, and that eq. 2 holds, independent of whether it is applied to alloys of different composition and of different degree of B2 order, or whether it is used for changes in $\Psi_{18 \mathrm{R}}$ during stabilisation.

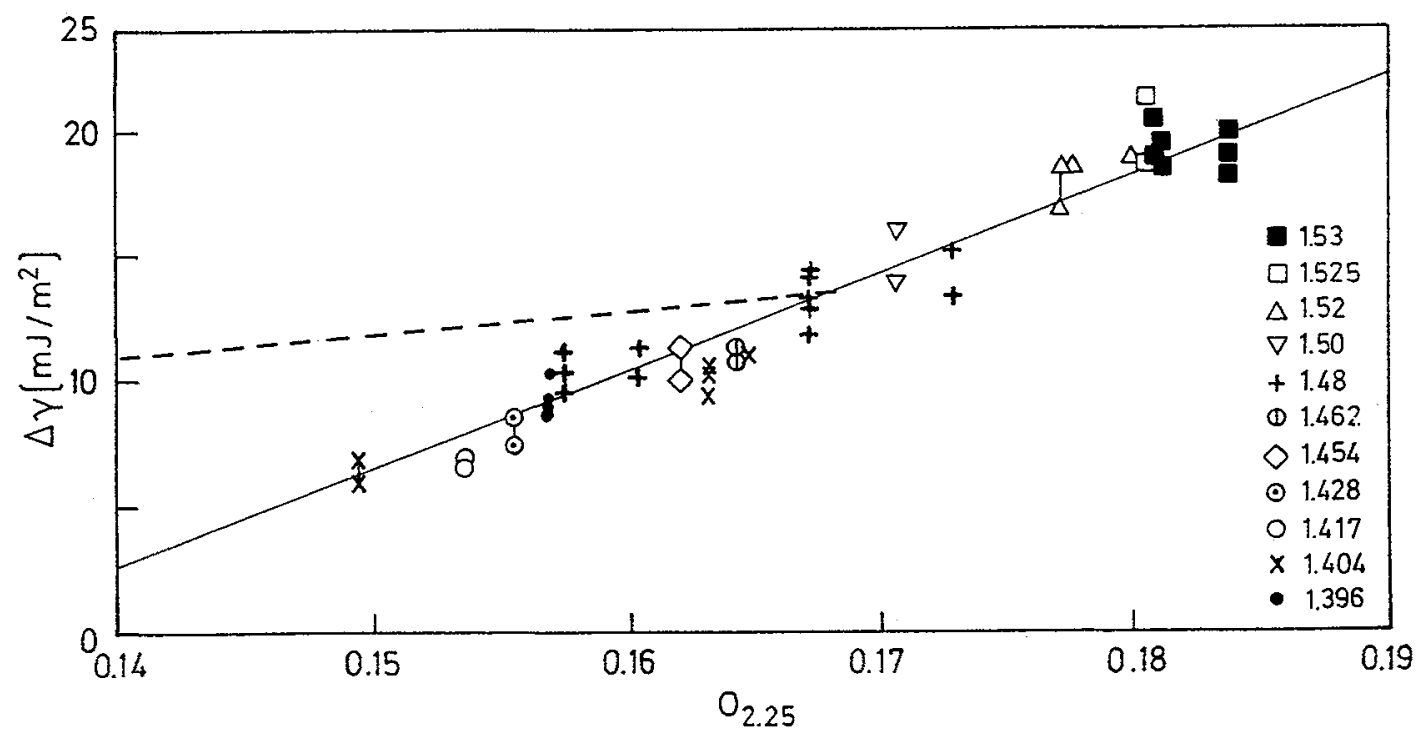

Fig. 3: $\Delta \gamma$ as a function of $\mathrm{O}_{2.25}$ defined by eq.6, for samples with different e/a. Broken line passes through $\Delta \gamma=0$ at $\mathrm{O}_{2.25}=0$.

With the help of eq. 2 changes in $\Delta \gamma$, denoted $\delta \Delta \gamma$, can be derived from measured changes in $\Psi_{18 \mathrm{R}}$ during stabilisation. On the other hand, the stabilisation leads to shifts in $\mathrm{M}_{\mathbf{S}}$, from which the corresponding modification in degree of long range order [3], and consequently changes in $\mathrm{O}_{2.25}$, denoted by $\delta \mathrm{O}_{2.25}$, can be deduced. Putting the results together the ratios $\delta \Delta \gamma / \delta \mathrm{O}_{2.25}$ are obtained. For the samples listed in table 5 of reference [3] we obtain, following the same sequence from sample M2 to M12 as there, the following values for $\delta \Delta \gamma / \delta \mathrm{O}_{2.25}: 57,35,107,100,81,93,93,78,58$ and $103 \mathrm{~m} \mathrm{~J} / \mathrm{m}^{2}$, with 
an average of $80 \mathrm{~m} \mathrm{~J} / \mathrm{m}^{2}$. The scatter is large, which is not surprising in view of the small changes in $\Psi_{18 \mathrm{R}}$ which are involved. It is clear however that this slope is very different from that of $400 \mathrm{~m} \mathrm{~J} / \mathrm{m}^{2}$ which describes the figure 3, and is given in eq 7 . Instead, it is close to that which is expected if $\Delta \gamma$ goes to zero simultaneously with the long range order energy. In figure 3 this dependence is traced by a broken line, which starts at the nonstabilised state of the average of these alloys, and leads to the slope of $78 \mathrm{~m} \mathrm{~J} / \mathrm{m}^{2}$. This is a very satisfactory result which implies that for a given alloy composition the stacking fault energy and enthalpy difference between $3 R(6 R)$ and $9 R(18 R)$ are proportional to the long range order energy and simultaneously to the square of the tetragonal distortion, but that the order energy influences the tetragonal distortion in different ways, depending on composition and electron concentration. Both effects together, ie the change in order and in composition, lead to the relationship of figure 3 for nonstabilised samples, which extrapolates to a finite degree of order when $\Delta \gamma$ becomes zero. These results point to a consistent description of the stacking fault energy in terms of a tetragonal distortion. However, the reason why the tetragonal distortion lowers the stacking fault energy has still to be established

We have discussed here the $\mathrm{Cu}-\mathrm{Zn}$-Al alloys. In many other SME alloys martensite structures with regular arrays of stacking faults are observed. In some of them, especially the Au alloys and $\mathrm{Ni}-\mathrm{Al}$ the order energy is so high that already the $3 \mathrm{R}$ face centered martensite is tetragonally distorted. A cubic reference state therefore does not exist, and the evaluation becomes more involved.

\section{THE STABILITY OF MARTENSITIC AND EQUILIBRIUM PHASES IN THE NOBLE METAL ALLOYS}

The 3R and $6 \mathrm{R}$ martensitic phases in $\mathrm{Cu}-\mathrm{Zn}-\mathrm{Al}$ are nearly cubic. The deviation is due to retained faults from $9 \mathrm{R}$ or $18 \mathrm{R}$. On their elimination by sufficiently high applied stresses the crystal becomes cubic. Therefore the $3 R$ and $6 R$ martensites differ from the disordered fec $\alpha$ phase solid solution only by their long range order. If the pair interchange energies are known, the energy difference between the ordered and disordered phases can be determined. One of the important advantages of the martensitic transformation is that the atom distribution is known in the martensite whenever it has been determined in the $\beta$ phase. This is due to the diffusionless nature of the martensitic transformation. In addition, since the martensitic transformation is induced at low temperatures, it is possible to obtain by an adequate heat treatment in $\beta$ a degree of order which comes close to the ideal value of eq. 5 .

The relationship between the different $\beta$ phase structures and the $3 R$ or $6 \mathrm{R}$ martensite is here schematically indicated.

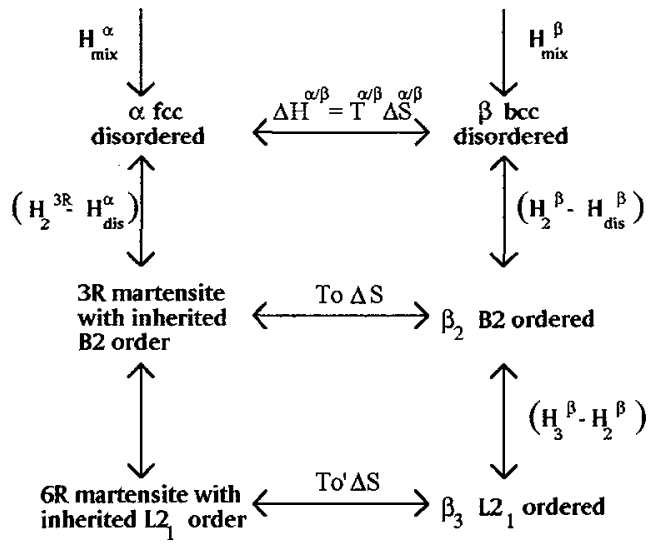

This diagram shows the enthalpies that are involved, and also serves to define some of the important quantities. $\mathrm{H}_{\text {mix }}^{\alpha}$ and $\mathrm{H}_{\text {mix }}^{\beta}$ are the enthalpies of mixing, starting from the pure elements in their standard 
states at atmospheric pressure and $25^{\circ} \mathrm{C} . \mathrm{H}_{\text {dis }}^{\alpha}$ and $\mathrm{H}_{\text {dis }}^{\beta}$ are those referred to the pure elements with the same structure. The enthalpy difference $\Delta \mathrm{H}^{\alpha / \beta}$ between disordered $\alpha$ and $\beta$ is determined by the equilibrium temperature $T^{\alpha / \beta}$ between both and the entropy difference $\Delta S^{\alpha / \beta}$. If $\alpha$ and $\beta$ are completely disordered $\Delta S^{\alpha / \beta}$ consists to the overwhelming part of the vibrational contribution. The long range order energies can be calculated once the i-th neighbor pair interchange energies are known. They are denoted $\mathrm{w}_{\mathrm{AB}}^{(\mathrm{i})}$ for the bcc phase, and $\mathrm{m}_{\mathrm{AB}}^{(\mathrm{i})}$ for the $\alpha$ phase for an $\mathrm{A}-\mathrm{B}$ pair. The equilibrium temperatures $\mathrm{T}_{\mathrm{o}}$ and $\mathrm{T}_{\circ}$ are close to the corresponding $M_{S}$ temperatures, the difference $\left(T_{0}-M_{S}\right)$ can here be neglected, considering that it is often of the same order of magnitude as the variation of $M_{S}$ from sample to sample with the same nominal composition. Thus if the pair interchange energies for $\alpha$ and $\beta$, the enthalpy differences $\Delta H^{\alpha / \beta}$ and the entropy of transformation $\Delta S$ are known, the $M_{S}$ temperatures can be predicted. Generally, however, $\Delta \mathrm{H}^{\alpha / \beta}$ cannot be determined experimentally with the required precision, and therefore $\Delta \mathrm{H}^{\alpha / \beta}$ are calculated from the $\mathrm{M}_{\mathrm{S}}$ temperatures.

Three problems will now be discussed: The $\Delta \mathrm{S}$ for martensitic transformations and their relationship with $\Delta \mathbf{S}^{\alpha / \beta}$, the composition dependence of $\Delta \mathrm{H}^{\alpha / \beta}$ and the pair interchange energies for fcc in the disordered and long range ordered state. A detailed evaluation of some of the points has been presented in $[8]$.

In figure 4 are shown the heats of mixing of the disordered $\alpha$ phase as a function of electron concentration for some binary noble metal alloys, as collected from the literature $[9,10]$. It can be seen that there are large differences between the various binary systems, and no correlation with the electron concentration e/a exists. This seems surprising since the stability range of the different equilibrium phases in the phase diagram depends on e/a.

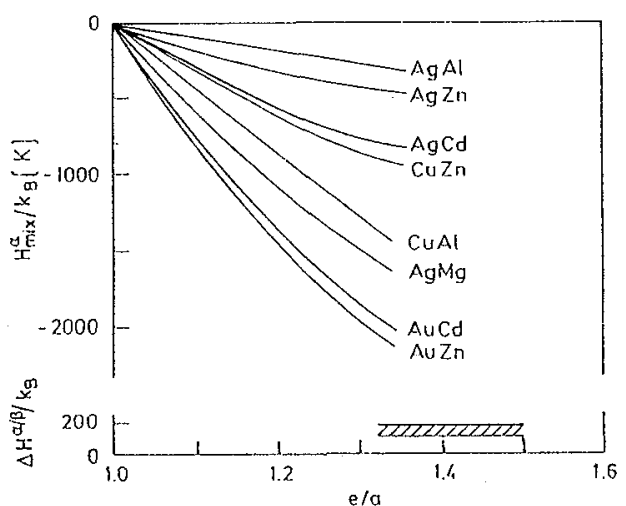

Fig. 4: Enthalpies of mixing $\mathrm{H}_{\text {mix }}^{\alpha}$ in the $\alpha$ phase with respect to the pure elements at their standard states as a function of e/a. At the bottom $\Delta H^{\alpha / \beta}$ from figure 6 in the same scale.

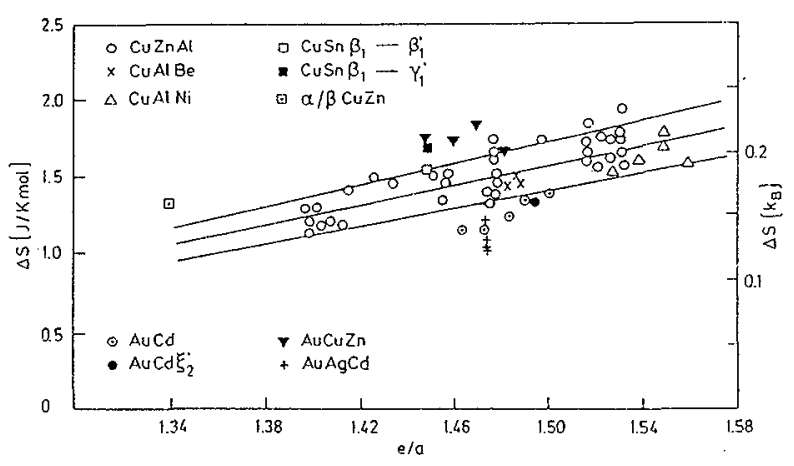

Fig. 5: Measured entropy differences $\Delta S$ for martensitic transformations in several noble metal alloys. $\Delta S^{\alpha / \beta}$ from $\alpha / \beta$ phase equilibrium at $902 \mathrm{~K}$ in $\mathrm{Cu}-\mathrm{Zn}$ denoted by $\alpha / \beta \mathrm{Cu}-\mathrm{Zn}$.

In figure 5 are collected entropy differences $\Delta \mathrm{S}$ for martensitic transformations in noble metal alloys $[11,12,8]$. The differences between $\mathrm{B} 2$ and $\mathrm{L} 2{ }_{1}$ ordered structures and between the different martensitic structures have been found to be too small to be detected, at least in the samples that have been studied $[1,11]$, and therefore are neglected. The most detailed results over the widest composition range are those for $\mathrm{Cu}-\mathrm{Zn}-\mathrm{Al}$. They show clearly that $\Delta \mathrm{S}$ increases with e/a. Some of the data for other alloys fall outside the range for the $\mathrm{Cu}$ alloys; whether this is real is not yet clear. It has to be kept in mind that $\Delta \mathrm{S}$ is often determined from the slope of the temperature dependent critical stress and from the transformation strain. 
An error of $10 \%$ in both quantities can easily account for the discrepancies. The main conclusion that can be drawn from figure 5 is that $\Delta \mathrm{S}$ depends mainly on e/a, but very little on the particular alloy system, in spite of the wide variety in heats of formation (fig.4), and in the tendency for long range order, as seen later.

In order to establish the relationship between the $\Delta \mathrm{S}$ from the martensitic transformation at low temperatures with the high temperature value $\Delta S^{\alpha / \beta}$ between the equilibrium $\alpha$ and $\beta$ phases, we assumed that at the highest temperatures available the $\alpha$ and $\beta$ phases are completely disordered, so that $\Delta S^{\alpha / \beta}$ is purely vibrational and that the equilibrium temperature $T^{\alpha / \beta}$ is in the middle of the two phase $(\alpha+\beta)$ region of the phase diagram. By subtracting the order contributions, we calculated from the martensitic transformation the $\Delta H^{\alpha / \beta}$ [2] and with $T^{\alpha / \beta}$ the desired $\Delta S^{\alpha / \beta}$. In figure 5 we show the resulting value for binary $\mathrm{Cu}-\mathrm{Zn}$. It can be seen that this $\Delta \mathrm{S}^{\alpha / \beta}$ is only slightly higher than that which is obtained from the martensitic transformation. Since it cannot be excluded that some short range order is retained in the $\beta$ phase at high temperatures, the discrepancy can be due also to a configurational contribution. The most important conclusion from figure 5 is that $\Delta S^{\alpha / \beta}$ and $\Delta S$ differ little, if at all, for $\mathrm{Cu}-\mathrm{Zn}$. Therefore it is expected that the same holds also for the other alloys, and that $\Delta S^{\alpha / \beta}$ generally is a function of e/a. It should be remarked that this e/a-dependence of $\Delta S^{\alpha / \beta}$ can fully account for the composition dependence of the $(\alpha+\beta)$ two phase region in the phase diagram at high temperatures, even if $\Delta \mathrm{H}^{\alpha / \beta}$ were composition independent [8].

Identifying now $\Delta S^{\alpha / \beta}$ with $\Delta S$ for all binary alloys, and using $T^{\alpha / \beta}$ in the middle of the two phase region, the resulting $\Delta \mathrm{H}^{\alpha / \beta}$ have been calculated for various binary noble metal alloy systems. The results are shown in figure 6 . The vertical bars correspond to the error limits which are indicated in figure 5 by the upper and lower lines. It can be noted that the $\Delta \mathrm{H}^{\alpha / \beta}$ depend very little on composition, that they all scatter around an average of $\Delta \mathrm{H}^{\alpha / \beta} \approx 140 \mathrm{k}_{\mathrm{B}}[\mathrm{K}]$, and that the strong dependence on the special alloy system, observed for $\mathrm{H}_{\text {mix }}^{\alpha}$ (fig. 4), is absent. It should also be noticed that the scale in figure 6 is inflated by about a factor 10 with respect to that of figure 4 . At the bottom of figure 4 is shown the range of $\Delta H^{\alpha / \beta}$ in the scale of this figure. It has to be concluded that the factors which control the enthalpy of formation of the $\alpha$ and $\beta$ phases are largely absent in the enthalpy difference $\Delta H^{\alpha / \beta}$ between $\alpha$ and $\beta$.

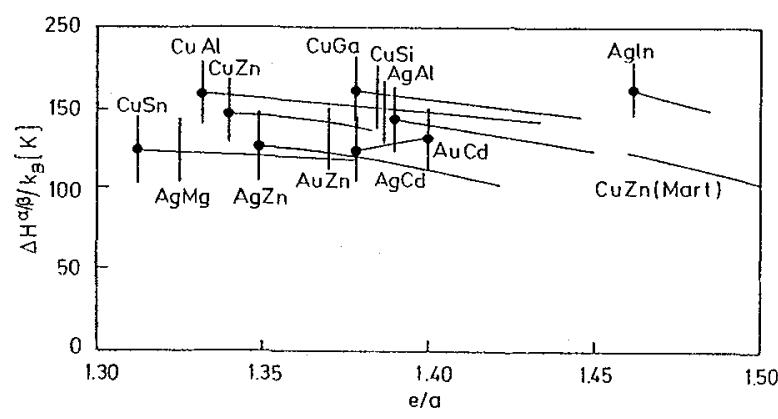

Fig. 6: Enthalpy differences $\Delta H^{\alpha / \beta}$ between $\alpha$ and $\beta$ phase in the middle of the $(\alpha+\beta)$ region as a function of e/a. $\mathrm{Cu} \mathrm{Zn}$ (Mart) from the martensitic transformation in $\mathrm{Cu}-\mathrm{Zn}$.

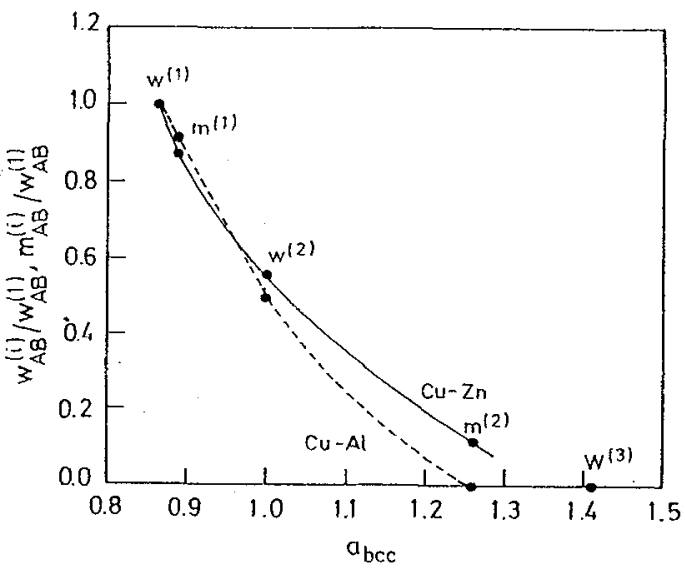

Fig. 7: Pair interchange energies versus pair distance in units of the bcc lattice constant, $a_{b c c}$ normalized by $\mathrm{w}_{\mathrm{AB}}^{(\mathrm{I})}$ for $\mathrm{Cu}-\mathrm{Zn}$ and $\mathrm{Cu}-\mathrm{Al}$.

This observation is the basis for the following model which attempts to describe quantitatively the stability of the martensite and the equilibrium phases in the noble metal alloys [8]: 
a) The enthalpy of formation of a disordered homogeneous phase with respect to the pure elements of the same structure, denoted $\mathrm{H}_{\text {dis }}^{\alpha}$ is the sum of a term which depends on the average lattice, and a term which takes into account the differences in the properties of the atomic species. The latter is described by pair interchange energies, which generally depend somewhat on composition and can extend to quite distant neighbor pairs. In the noble metal alloys the neglect of the composition dependence and of contributions from third and more distant neighbor pairs leads already to good results.

b) The enthalpies of formation of the average periodic lattice are mainly a function of electron concentration e/a, as is well known from the simple nearly free electron models or their more sophisticated versions.

c) the pair interchange energies for each alloy system depend on the pair distance but otherwise are structure independent, and therefore can be interpolated. They vary very strongly from one alloy system to the other.

d) The pair interchange energies which determine the enthalpies of formation of the disordered phases are the same that are responsible for the long range order enthalpies and critical ordering temperatures.

e) The vibrational entropy difference depends mainly on e/a, but is rather independent of degree of long range order, heat of formation and temperature, as discussed above. For the martensitic transformation and for the $\alpha / \beta$ stability it is written as (figure 5):

$$
\Delta \mathrm{S}=(0.345 \mathrm{e} / \mathrm{a}-0.337) \mathrm{k}_{\mathrm{B}}
$$

With these ingredients it is possible to describe quantitatively the stabilities of the martensites, and of the disordered and ordered $\alpha$ and $\beta$ equilibrium phases in the noble metal alloys.

Writing the enthalpies of formation of the disordered $\alpha$ fcc and $\beta$ bcc phases with respect to the pure elements with the same structure as the sum of a term which depends only on e/a and another one which is a function of the pair interchange energies, as

$$
\begin{array}{ll}
\mathrm{H}_{\mathrm{dis}}^{\alpha}=\mathrm{H}_{0}^{\alpha}(\mathrm{e} / \mathrm{a})-\mathrm{A}_{\mathrm{dis}}^{\alpha} \mathrm{C}_{\mathrm{A}} \mathrm{C}_{\mathrm{B}} & ; \mathrm{H}_{\mathrm{dis}}^{\beta}=\mathrm{H}_{0}^{\beta}(\mathrm{e} / \mathrm{a})-\mathrm{A}_{\mathrm{dis}}^{\beta} \mathrm{C}_{\mathrm{A}} \mathrm{C}_{\mathrm{B}} \\
\mathrm{A}_{\mathrm{dis}}^{\alpha}=6 \mathrm{~m}_{\mathrm{AB}}^{(1)}+3 \mathrm{~m}_{\mathrm{AB}}^{(2)} & ; \mathrm{A}_{\mathrm{dis}}^{\beta}=4 \mathrm{w}_{\mathrm{AB}}^{(1)}+3 \mathrm{w}_{\mathrm{AB}}^{(2)}
\end{array}
$$

we require, in order that $\Delta \mathrm{H}^{\alpha / \beta}=\mathrm{H}_{\mathrm{dis}}^{\beta}-\mathrm{H}_{\mathrm{dis}}^{\alpha}$ is independent of the special alloy system, and is a function only of e/a, that

$$
\mathrm{A}_{\mathrm{dis}}^{\alpha}=\mathbf{A}_{\mathrm{dis}}^{\beta}
$$

If the volume does not change on transformation, if $m_{A B}^{(1)}$ is linearly interpolated between $w_{A B}^{(1)}$ and $\mathrm{w}_{\mathrm{AB}}^{(2)}$ and a ratio $\mathrm{w}_{\mathrm{AB}}^{(2)} / \mathrm{w}_{\mathrm{AB}}^{(1)}=0.56$ from long range order in $\mathrm{Cu}-\mathrm{Zn}$ is used, we obtain [8]

$$
\mathrm{m}_{\mathrm{AB}}^{(1)}=0.9182 \mathrm{w}_{\mathrm{AB}}^{(1)}
$$

For $\mathrm{m}_{\mathrm{AB}}^{(2)}$ follows, assuming the validity of eq. 10 with the neglect of more distant pair contributions:

$$
\mathrm{m}_{\mathrm{AB}}^{(2)}=0.057 \mathrm{w}_{\mathrm{AB}}^{(1)}
$$

In figure 7 are shown the pair interchange energies, normalised to $w_{A B}^{(1)}$ as a function of pair distance for $\mathrm{Cu}-\mathrm{Zn}$ and $\mathrm{Cu}-\mathrm{Al}$. For $\mathrm{Cu}-\mathrm{Al} \mathrm{m}_{\text {CuAl }}^{(\mathrm{l})}$ is obtained by a linear interpolation which is quite satisfactory, whereas for $\mathrm{Cu}-\mathrm{Zn}$ a curvature is included. In both cases eq. 10 is assumed to hold. The $\mathrm{w}_{\mathrm{AB}}^{(\mathrm{i})}$ and $\mathrm{m}_{\mathrm{AB}}^{(\mathrm{i})}$ that can best describe all experimental results for $\mathrm{Cu}-\mathrm{Zn}$ and $\mathrm{Cu}-\mathrm{Al}$ are the following [8]

$$
\begin{aligned}
& \mathrm{w}_{\text {CuZn }}^{(1)}=955 \mathrm{k}_{\mathrm{B}}[\mathrm{K}] ; \mathrm{w}_{\mathrm{CuZn}}^{(2)}=535 \mathrm{k}_{\mathrm{B}}[\mathrm{K}] ; \mathrm{m}_{\mathrm{CuZn}}^{(1)}=845 \mathrm{k}_{\mathrm{B}}[\mathrm{K}] ; \mathrm{m}_{\mathrm{CuZn}}^{(2)}=115 \mathrm{~K}_{\mathrm{B}}[\mathrm{K}] \\
& \mathrm{w}_{\text {CuAl }}^{(1)}=1650 \mathrm{k}_{\mathrm{B}}[\mathrm{K}] ; \mathrm{w}_{\text {CuAd }}^{(2)}=825 \mathrm{k}_{\mathrm{B}}[\mathrm{K}] ; \mathrm{m}_{\text {CuAl }}^{(1)}=1512 \mathrm{k}_{\mathrm{B}}[\mathrm{K}] ; \mathrm{m}_{\text {CuAl }}^{(2)}=0
\end{aligned}
$$

Thus the postulate that the pair interchange energies are structure insensitive is compatible with the observation that $\Delta \mathrm{H}^{\alpha / \beta}$ depends mainly on e/a in the noble metal alloys (figure 6) through the validity of eq. 10 . 


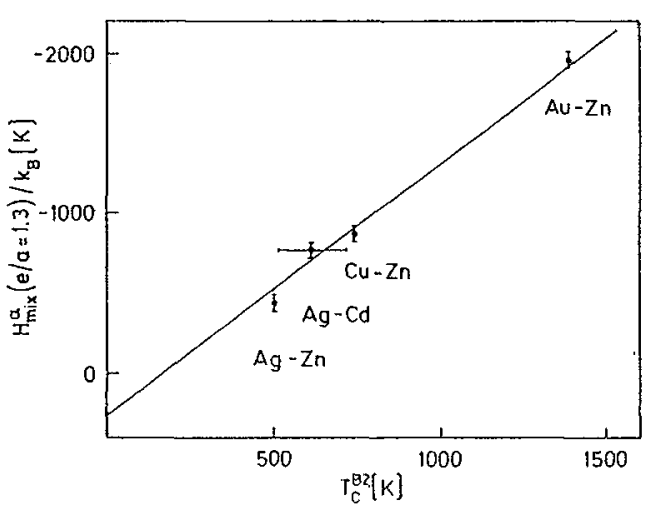

Fig.8: Enthalpy of mixing in the $\alpha$ phase at e/a $=1.3$ as a function of the critical B2 ordering temperature $\mathrm{T}_{c}{ }^{\mathrm{B} 2}$ at equiatomic composition for the alloys indicated.

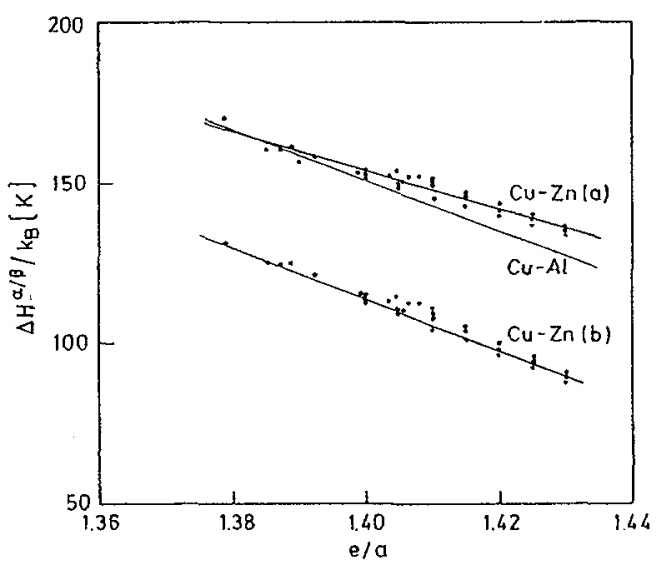

Fig. 9: $\Delta \mathrm{H}^{\alpha / \beta}$ calculated from the martensitic transformation for $\mathrm{Cu}-\mathrm{Zn}$ and $\mathrm{Cu}-\mathrm{Al}$ as a function of e/a. For $\mathrm{Cu}-\mathrm{Al}$ and upper $\mathrm{Cu}-\mathrm{Zn}$ curve (a) pair interchange energies from eq.13, lower $\mathrm{Cu}-\mathrm{Zn}$ curve (b) those from eqs. 11 and 12.

The claim that the pair interchange energies for the disordered phases and those responsible for long range order are closely the same can best be evidenced by figure 8 . In this figure is shown the relationship between the enthalpy of mixing at $\mathrm{e} / \mathrm{a}=1.3$, taken from figure 4 , and the critical B2 ordering temperature for four binary alloys with a two valent second component: There is an excellent linear dependence between both, stressing the correlation between the pair interchange energies responsible for the enthalpy of mixing in the $\alpha$ phase and those which determine the order energy in the $\beta$ phase. The extrapolation to $T_{c}^{B 2}=0$ permits to obtain the part in $H_{\text {mix }}^{\alpha}$ which is independent of the pair interchange energies. $\mathrm{H}_{\text {mix }}^{\alpha}$ in these alloys is different from $\mathrm{H}_{\text {dis }}^{\alpha}$, since the structures of the pure elements in their standard states are different. The critical $B 2$ ordering temperatures have been determined from the cluster variation method and can be written in the following compact form [14]

$$
\mathrm{k}_{\mathrm{B}} \mathrm{T}_{\mathrm{c}}^{\mathrm{B} 2}=2 \kappa_{1} \mathrm{w}_{\mathrm{AB}}^{(1)}-1.5 \kappa_{2} \mathrm{w}_{\mathrm{AB}}^{(2)} ; \kappa_{1}=0.811, \kappa_{2}=1.0
$$

In the Bragg - Williams - Gorski approximation $\kappa_{1}=\kappa_{2}=1$. Using $\mathrm{w}_{\mathrm{AB}}^{(2)} / \mathrm{w}_{\mathrm{AB}}^{(1)}=0.56$ and the $\mathrm{m}_{\mathrm{AB}}^{(\mathrm{i})}$ from eqs. 11 and 12, the slope in figure 8 can be quantitatively accounted for [8].

Knowing the pair interchange energies, it is possible to calculate from the $M_{S}$ temperatures and $\Delta S$ (eq.8) the $\Delta H^{\alpha / \beta}$. This has been done in figure 9 for $\mathrm{Cu}-\mathrm{Zn}$ and $\mathrm{Cu}-\mathrm{Al}$. For $\mathrm{Cu}-\mathrm{Zn}$ measured $\mathrm{M}_{\mathrm{S}}$ temperatures between $\beta$ and $9 \mathrm{R}$ have been used [15]. For $\mathrm{Cu}-\mathrm{Al}$ the experimentally determined enthalpy differences between $\mathrm{B} 2$ and $9 \mathrm{R}$ in ternary $\mathrm{Cu}-\mathrm{Zn}-\mathrm{Al}$ have been extrapolated [11]. The difference between $3 R$ and $9 R$ [1] has been duly taken into account. If the pair interchange energies of eq.13 are used, the upper curve (a) for $\mathrm{Cu}-\mathrm{Zn}$ is obtained. It agrees with that for $\mathrm{Cu}-\mathrm{Al}$, and coincides with that from ab initio calculations for $\mathrm{Cu}-\mathrm{Zn}$ [16]. (The latter curve has not been drawn, because it is taken from the small relevant figure in [16] with some uncertainty). If we had used the $\mathrm{m}_{\mathrm{Cuzn}}^{(\mathrm{i})}$ values obtained from a linear interpolation between $w_{C u z_{n}}^{(1)}$ and $w_{C u z_{n}}^{(2)}$, eqs.11 and 12, we would have obtained the lower curve in figure 9. This shows that small changes in $m_{A B}^{(i)}$ can have a quite large effect on the calculated $\Delta H^{\alpha / \beta}$. The upper curve for $\mathrm{Cu}-\mathrm{Zn}$ in figure 9 is preferred to the lower one, since it coincides better with that for $\mathrm{Cu}$ $\mathrm{Al}$ and with that from the $\mathrm{ab}$ initio calculations. In addition, the $\mathrm{m}_{\mathrm{AB}}^{(\mathrm{i})}$ from eq.13 lead to a $\mathrm{O}_{2.25}$ (eq.4) 
which relates well to $\Delta \gamma$. Finally, the fact that the $\Delta H^{\alpha / \beta}$ in figure 6 are so similar for a large number of noble metal alloys with widely different pair interchange energies also favors the claim that $\Delta \mathrm{H}^{\alpha / \beta}$ for $\mathrm{Cu}-\mathrm{Zn}$ and $\mathrm{Cu}-\mathrm{Al}$ should not differ.

A linear extrapolation to pure $\mathrm{Cu}$ of the upper $\mathrm{Cu}-\mathrm{Zn}$ curve leads to $390 \mathrm{k}_{\mathrm{B}}[\mathrm{K}]$, the lower one yields $430 \mathrm{k}_{\mathrm{B}}[\mathrm{K}]$ and that from $\mathrm{Cu}-\mathrm{Al}$ a value of $450 \mathrm{k}_{\mathrm{B}}[\mathrm{K}]$. These numbers are close to the $\Delta \mathrm{H}^{\alpha / \beta}$ of $440 \mathrm{k}_{\mathrm{B}}[\mathrm{K}]$ which are reported in the literature for pure $\mathrm{Cu}$ at room temperature [17]. From this value for $\mathrm{Cu}$ and an average between $\mathrm{Cu}-\mathrm{Zn}$ (a) and $\mathrm{Cu}-\mathrm{Al}$ we obtain as a reasonable estimate for the e/a dependence of $\Delta \mathrm{H}^{\alpha / \beta}$ :

$$
\Delta \mathrm{H}^{\alpha / \beta}=(1160-720 \mathrm{e} / \mathrm{a}) \mathrm{k}_{\mathrm{B}}[\mathrm{K}]
$$

This smooth e/a dependence of $\Delta \mathrm{H}^{\alpha / \beta}$ makes it unnecessary to include additional contributions at some critical e/a due to nesting effects.

Restricting ourselves to first and second neighbor pair interchange energies, a good quantitative evaluation of the factors that control the stability of the equilibrium and the martensitic phases could be obtained. However, it has to be kept in mind that small changes in the $\mathrm{m}_{\mathrm{AB}}^{(\mathrm{i})}$ and $\mathrm{w}_{\mathrm{AB}}^{(\mathrm{i})}$ are possible, on the one hand due to variations with composition which have not been considered here, and secondly; because due to incomplete electron screening Friedel oscillations in the pair interchange energies at large pair distances cannot be excluded. These deviations, although small, can be sufficiently large to account for the small variations in equilibrium temperature $T^{\alpha / \beta}$ between the equilibrium $\alpha$ and $\beta$ phases of the different alloy systems.

\section{Acknowledgements}

The support of the Argentinian Fundación Antorchas is gratefully acknowledged.

\section{References}

[1] M. Ahlers and J.L. Pelegrina, Acta metall mater 40, 3213 (1992).

[2] F. Saule, M. Ahlers, F. Kropff and E.B. Rivero, Acta metall mater 40, 3229 (1992).

[3] F. Saule and M. Ahlers, Acta metall mater 43, 2373(1995).

[4] P.C.J. Gallagher, Met. Trans 1, 2429 (1970).

[5] M. Ahlers, Phys Stat Sol (b) 172, 65 (1992).

[6] L. Delaey, M. Chandrasekaran, M. Andrade and J, van Humbeeck, Proc. Int: Conf. Solid-Solid Phase Transformation (edited by H.I. Aaronson et al.) p.1429. Metall Soc. A.I.M.E. Warrendale, Pa (1982).

[7] M. Ahlers, Progr Mat Science 30, 135 (1986).

[8] M. Ahlers, Zeitschr Physik B, accepted (1995).

[9] R. Hultgren, R.L. Orr, P.D. Anderson and K.K. Kelley, eds. Selected Values of Thermodynamic

Properties of Metals and Alloys, John Wiley 1963.

[10] B. Predel, in Landolt - Börnstein New Series Group IV, Vol 5a, Springer 1990.

[11] J.L. Pelegrina and M. Ahlers, Acta metall mater 40, 3205 (1992).

[12] J.R. Romero and J.L. Pelegrina, Phys Rev B 50, 9046 (1994).

[13] M. Ahlers, J. Phys.: Cond.Matter 5, 8129 (1993).

[14] M. Ahlers, Phil Mag A 70, 247 (1994).

[15] R. Romero and M. Ahlers, J.Phys.: Cond. Matter 1, 3191 (1989).

[16] P.E.A.Turchi, M. Sluiter, F.J. Pinski, D.D. Johnson, D.M. Nicholson, G.M. Stocks and J.B. Staunton, Phys Rev Letters 67, 1779 (1991).

[17] A.T. Dinsdale, Calphad 15, 317 (1991) 